\title{
Phosphoproteomic profiling of arsenite-treated human small airway epithelial cells
}

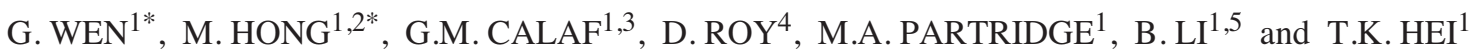 \\ ${ }^{1}$ Center for Radiological Research, Columbia University Medical Center, New York, NY, USA; ${ }^{2}$ College of Life Science, \\ South China Agricultural University, Guangzhou, P.R. China; ${ }^{3}$ Instituto de Alta Investigación, Universidad de Tarapacá, \\ Arica, Chile; ${ }^{4}$ Department of Natural Sciences, Hostos College of the City University of New York, Bronx, NY, USA; \\ ${ }^{5}$ School of Radiation Medicine and Public Health, Soochow University, Soochow, P.R. China
}

Received July 27, 2009; Accepted September 7, 2009

DOI: 10.3892/or_00000649

\begin{abstract}
Arsenic is well documented as a chemotherapeutic agent capable of inducing cell death; however, it is also considered as a human carcinogen. Although it has recently been shown that arsenite exposure can potentiate genotoxicity, little is known about its global effects exerted in cells at the proteome level. Immortalized human small airway epithelial cells exposed to arsenite were used to identify phosphoproteins of two major signaling cascades, such as the human phospho-receptor tyrosine kinase (Phospho-RTK) and the mitogen-activated protein kinases (MAPKs). These two arrays included several phosphoproteins, such as EGFR, ErbB2, ErbB4, InsulinR, Flt-3, extracellular signal-regulated kinases (ERK1/2), intracellular kinases such as AKT, GSK-3, c-Jun N-terminal kinases (JNK1-3) and different p38 isoforms $(\alpha / \beta / \delta / \gamma)$. In arsenite-treated cells, phosphorylation of EGFR, InsulinR and Flt3R showed an increase when compared to their non-arsenite treated counterparts. Inhibitors of these proteins further confirmed the involvement of such proteins in the neoplasm transformation of arsenite-treated human small airway epithelial cells as seen in changes in plating efficiency, anchorage-independent growth and proliferation rate. It can be concluded that analysis of phosphoprotein by using phosphoproteomic profiling can be very useful to understand the mechanism of arsenite-induced carcinogenesis.
\end{abstract}

\section{Introduction}

Arsenite is well documented as a chemotherapeutic agent capable of inducing cell death, while at the same time, it is

Correspondence to: Dr Gengyun Wen, Centre for Radiological Research, Columbia University, New York, NY 10032, USA E-mail: gw2154@columbia.edu

*Contributed equally

Key words: arsenite, phosphor-receptor tyrosine kinases, mitogenactivated protein kinases, phosphoproteomic profiling also considered as a known human carcinogen $(1,2)$. Epidemiological studies have shown that chronic exposure to arsenite is common in living environment which results in liver injury, peripheral neuropathy, keratosis, and increased incidence of cancer in the lung, skin, bladder and liver (3). Human cells are more sensitive to arsenite than other species due to a lower efficiency of arsenite methylation in humans (4). A close relationship between exposure to arsenite and increasing incidence of cancer in different countries where people are prone to arseniasis has been established (5-9). The importance of the toxicological effect of this chemical places it among the top priority hazards in the world $(10,11)$. Unlike many other carcinogens, arsenite is more likely to behave as a mutagenic substance since not only can it cause point mutations, but it has also been shown to induce large deletion mutations (12). These multi-locus deletions are incompatible with cell survival and measurements at gene loci that are closely linked to essential genes. Accumulating evidence has shown that arsenite exposure induces chromosomal aberration, aneuploidy and micronuclei formation, suggesting that arsenite and its derivatives may play a role in tumor promotion (13).

Carcinogenic effects of arsenite act principally via an epigenetic mechanism. It has been shown that arsenite can induce reactive oxygen species production and cause DNA damage (13-16). It may also interfere with the DNA repair system or DNA methylation state, induce inhibition of p53, increase cell proliferation, and alter signal transduction pathways that lead to the activation of transcription factors (17-20). However, knowledge on the exact carcinogenic mechanism and valid model systems for this compound is still lacking, which creates even more concern for adverse potential of this important environmental pollutant (21).

Although recent studies have suggested that arsenite exposure can cause genotoxicity, little is known about the global effects exerted in cells at the proteomic level. Proteomics has been demonstrated to be a powerful tool in the study of functional proteins in systems under certain pathogenic and toxic conditions in response to drugs $(22,23)$. Phosphoproteomics, a subdivision of proteomics, is specifically dealing with dynamics of intracellular protein phosphorylation (24). Protein phosphorylation is estimated to constitute $30 \%$ of the 
proteome and is a major regulatory mechanism that controls many basic cellular processes. While phosphoproteomics greatly expands the knowledge of different phosphoproteins, its greatest promise is to obtain information on intracellular protein phosphorylation-based signaling network. Emerging technologies that are likely to have important impact on phosphoproteomics include protein and antibody microarray $(24,25)$ which can be used to analyze differentially expressed phosphoproteins by comparing them in a two-dimensional array.

Several receptor tyrosine kinases such as EGFR, InsulinR, Flt3R, and proteins within the MAP-kinase pathways such as ERK 1/2 and AKT that ultimately lead to neoplastic progression of cells were analyzed $(27,28)$ and showed that there was activation by arsenite exposure. Immortalized human small airway epithelial cells by ectopic expression of telomerase were used to analyze the phosphoproteomes of two major signaling cascades, such as the human phosphoreceptor tyrosine kinase (Phospho-RTK) pathway and the mitogen-activated protein kinases (MAPKs) with antibody phosphoproteome arrays to identify key components that were regulated during the course of arsenite-induced carcinogenesis. The Phospho-RTK included EGFR, ErbB2, ErbB4, InsulinR-1, IGFR-1, and Flt3. The MAPKs included extracellular signal-regulated kinases (ERK1/2), intracellular kinases such as AKT, GSK-3, p70 S6, c-Jun N-terminal kinases (JNK1-3) and different p38 isoforms $(\alpha / \beta / \delta / \gamma)$. Therefore, studying the proteome of these two major signaling pathways is likely to contribute to a better understanding of mechanisms related to arsenite-induced carcinogenesis.

\section{Materials and methods}

Cell culture. SAEC h-TERT immortalized cells were cultured in SAGM medium supplemented with various growth factors supplied by the manufacturer (SAGM SingleQuots, Cat \#: CC4124, Cambrex Bio Science Walkersville, Inc., Walkersville, MD) and maintained at $37^{\circ} \mathrm{C}$ in a humidified $5 \% \mathrm{CO}_{2}$ incubator. There were 4 experimental groups: 1) SAEC cells as control group (Ctrl); SAEC cells cultured in the presence of 2) $0.5 \mu \mathrm{g} / \mathrm{ml}$ sodium arsenite for 3 months, designated as SAEC-A0.5-3M; 3) $2.0 \mu \mathrm{g} / \mathrm{ml}$ sodium arsenite for 3 months, designed as SAEC-2.0-3M; and 4) $0.5 \mu \mathrm{g} / \mathrm{ml}$ sodium arsenite for one year, designated as SAEC-A0.5-1Y.

Growth kinetics and plating efficiency assay. To determine the effect of arsenite on growth rate and saturation density, control SAEC, SAEC-A0.5-3M, SAEC-A2.0-3M and SAECA0.5-1Y cells were plated at a density of $2 \times 10^{5}$ cells from exponentially growing cultures and were replated in $60-\mathrm{mm}$ diameter dishes. At each time point, triplicate dishes from each group were trypsinized and total number of cells per dish was determined. Plating efficiency (PE), a measure of the number of colonies originating from single cells, was used for determining the effects of arsenite treatment. PE was determined by the following formulae: $\mathrm{PE}(\%)$ is equal to the number of colonies counted divided by the number of cells inoculated and multiplied per 100.

CyQuant cell growth assay. Proliferation was assessed by CyQuant NF cell proliferation assay kit (Invitrogen). Briefly, cells were cultured in a 96-well plate overnight. Then cells were washed with PBS and incubated for $1 \mathrm{~h}$ by addition of fluorescence dye. Fluorescence intensity was measured with excitation at $485 \mathrm{~nm}$ and emission detection at $530 \mathrm{~nm}$ on an automatic microplate reader (Biotek Instruments, Inc., Winooski, VT). A preliminary study with the proliferation assay showed that absorbance was directly proportional to the number of cells. Data were determined as proliferation rate measured by fluorescence density.

Anchorage-independent assay. To test for soft-agar colony growth capacity, all the control and sodium arsenite treated SAEC cells were plated at a density of $1 \times 10^{3}$ cells in $1 \mathrm{ml}$ of $0.35 \%$ agarose over a $0.7 \%$ agar base in a 24 -well culture plate. Cultures were fed every 3 days and colonies with $>50$ cells were scored after 4 weeks in cultures under a dissecting microscope.

Preparation of cell lysate for proteomic profiling. To identify the phosphoproteomic profiles, the Proteome Profiler ${ }^{\mathrm{TM}}$ antibody array of human phospho-RTK and human phosphoMAPK array kits (R\&D Systems, Inc. Minneapolis, MN) $(25,29)$ were used. Cell lysates from control and arsenitetreated SAEC were prepared by rinsing initially with PBS solution and then dissolved at $\geq 1 \times 10^{7}$ cells $/ \mathrm{ml}$ in lysis buffer 6 (R\&D Systems, Inc.) and kept at $2-8^{\circ} \mathrm{C}$ for $30 \mathrm{~min}$. It was then centrifuged at $14,000 \mathrm{x} \mathrm{g}$ at $4^{\circ} \mathrm{C}$ for $5 \mathrm{~min}$ and the supernatant was transferred to a new Eppendorf tube and put onto ice prior to use. The protein concentration was also determined at this stage by using the Bio-Rad total protein assay kit (Bio-Rad, Hercules, CA). About 100-300 $\mu \mathrm{g}$ of lysate with a maximum allowable lysate volume of $250 \mu \mathrm{l} /$ array was used immediately for this purpose. Any extra lysate was aliquoted and stored at $-70^{\circ} \mathrm{C}$ for future use. A 5:1 ratio of array buffer 1 (R\&D Systems, Inc.) to lysis buffer 6 was used for optimal assay performance.

Differential array hybridization. Array buffer 1 (1.5 ml) was used in each well of the 4-well multi-dish. One array was placed into each well with array number faced upward and incubated for $1 \mathrm{~h}$ on a rocking platform shaker at room temperature. Desired quantity of lysate was mixed with $1.25 \mathrm{ml}$ of array buffer 1 and lysis buffer 6 to a total volume of $1.5 \mathrm{ml}$ in a separate tube. Then, array buffer 1 was removed from each well and filled with a lysate volume of $250 \mu \mathrm{l} /$ array and continue the incubation overnight at $2-8^{\circ} \mathrm{C}$ on the rocking platform shaker. After that each array was removed from the 4-well multi-dish, placed in individual plastic container and washed with $20 \mathrm{ml}$ of $1 \mathrm{X}$ wash buffer by soaking for 10 min with continuous shaking and the process was repeated successively 3 times. The 4-well multi-dishes were rinsed thoroughly with deionized water and dried. After washing, each array membrane was again placed in the well. For each array, $15 \mu \mathrm{l}$ of detection antibody cocktail concentrate was diluted to $1.5 \mathrm{ml}$ with $1 \mathrm{X}$ array buffer $2 / 3$ and added per well, incubated for $2 \mathrm{~h}$ at room temperature with shaking. The arrays were then washed as mentioned earlier. Streptavidin$\operatorname{HRP}(1: 2000)$ was diluted in $1 \mathrm{X}$ array buffer $2 / 3$ and $1.5 \mathrm{ml}$ of it was added into each well. Then the arrays were carefully removed from wash buffer (with complete draining of excess 
wash buffer) and put back to each well of the 4-well multidish containing the diluted Streptavidin-HRP, covered with the lid, and incubated for $30 \mathrm{~min}$ at room temperature with shaking. Arrays were again washed as mentioned earlier.

Chemiluminescence detection. Each array was removed from the wash buffer, allowed to drain completely and covered with a plastic sheet protector. Each array membrane was covered with $1.0 \mathrm{ml}$ of chemiluminescent substrate and incubated at room temperature for 2-5 $\mathrm{min}$. The membranes were taken out and completely drained of chemiluminescent reagent, covered with swaron wrap and exposed to X-ray film (Kodak BioMax MS film; Kodak Corp., Rochester, NY) with a corresponding intensifying screen at room temperature, for multiple exposures of 1-5 min.

Quantification of hybridization array. Quantification of hybridization signals on the expression array membranes was carried out by exposing the autoradiographic film in a densitometric scanner (model 300A; Molecular Dynamics, Sunnyvale, CA). It was then estimated both with the ImageQuant (Molecular Dynamics) and ScanAlyze program (Eisen Lab). Volume quantification was performed by calculating the volume under the surface created by a threedimentional plot of pixel locations and pixel values as described (30).

All raw signal intensities were corrected for background by subtracting the signal intensity of a negative control or blank. Results were also normalized to that of three pairs of positive control spots in the corner of each array. These corrected, normalized signals can then be used to estimate the relative abundance of particular phosphorylated proteins. To delineate the potential signal interference between adjacent strong hybridization signals, equal-sized ellipses were drawn around each signal area (hybridization spots) using software (ImageQuant/ScanAnalyze) and was then separately scanned and compared with positive control spots, so the chances of interference between adjacent strong hybridization signals were minimized.

Normalization of the expression levels of different phosphorylated proteins from multiple autoradiographic exposures between different hybridization experiments were done by taking the average signals of each of the positive control spots. Data from high intensity spots were chosen for further use. Median background was subtracted, and signals that were $<1.5$-fold above background level were considered too low to accurately measure and were omitted from the analysis. Signals for each protein spots were also normalized to the geometric mean of the expression level of that protein across the set of membranes being compared. Mean signals were calculated from two measurable spots, or if one of the two spots were measurable.

Western blot analysis. Protein was extracted by lysing the cells in extraction buffer (50 mM Tris- $\mathrm{HCl}, \mathrm{pH} 8.0,150 \mathrm{mM}$ $\mathrm{NaCl}, 1 \% \mathrm{NP}-40,0.1 \%$ sodium dodecyl sulfate and $1 \mathrm{mM}$ phenylmethylsulfonyl fluoride). The protein concentration was determined by Bio-Rad protein Assay (Bio-Rad). Equivalent amounts of protein $(30 \mu \mathrm{g})$ were fractionated by electrophoresis in SDS-polyacrylamide gel. The protein was
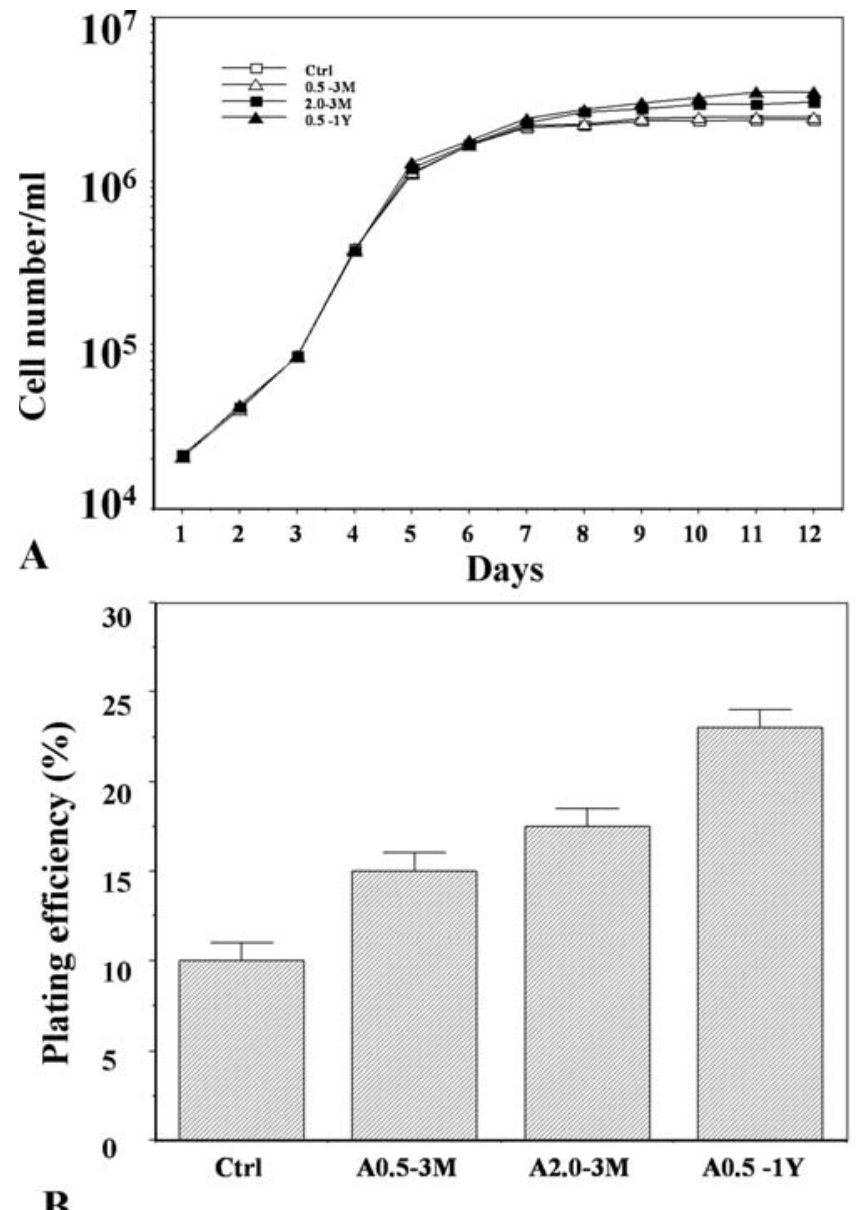

B

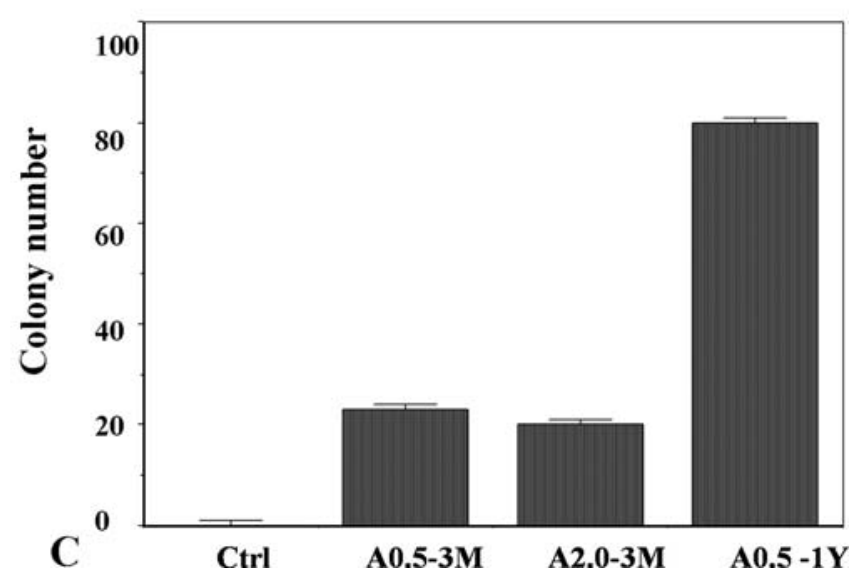

Figure 1. Growth characteristics of arsenite-treated SAEC cells (A) Growth rate for arsenite-exposed SAEC cells. (B) Plating efficiency (\%) for arseniteexposed SAEC cells. (C) Anchorage-independent growth of arsenite-treated SAEC cells. The cells were continuously treated for 3 months with $0.5 \mu \mathrm{g} / \mathrm{ml}$ (A0.5-3M) and $2.0 \mu \mathrm{g} / \mathrm{ml}(\mathrm{A} 2.0-3 \mathrm{M})$ and for 1 year with $0.5 \mu \mathrm{g} / \mathrm{ml}(\mathrm{A} 0.5-1 \mathrm{Y})$ sodium arsenite.

subsequently transferred to PVDF membranes under semidry conditions. Antibodies for different RTKs and MAPKs (Santa Cruz Biotechnology, Inc.) were applied to probe the membranes. The secondary antibodies (anti-rabbit or antimouse) (Amersham Biosciences, Piscataway, NJ) were conjugated to horseradish peroxidase (dilution 1:50001:10000). Signals were detected using the ECL system (Amersham Biosciences) (31). 

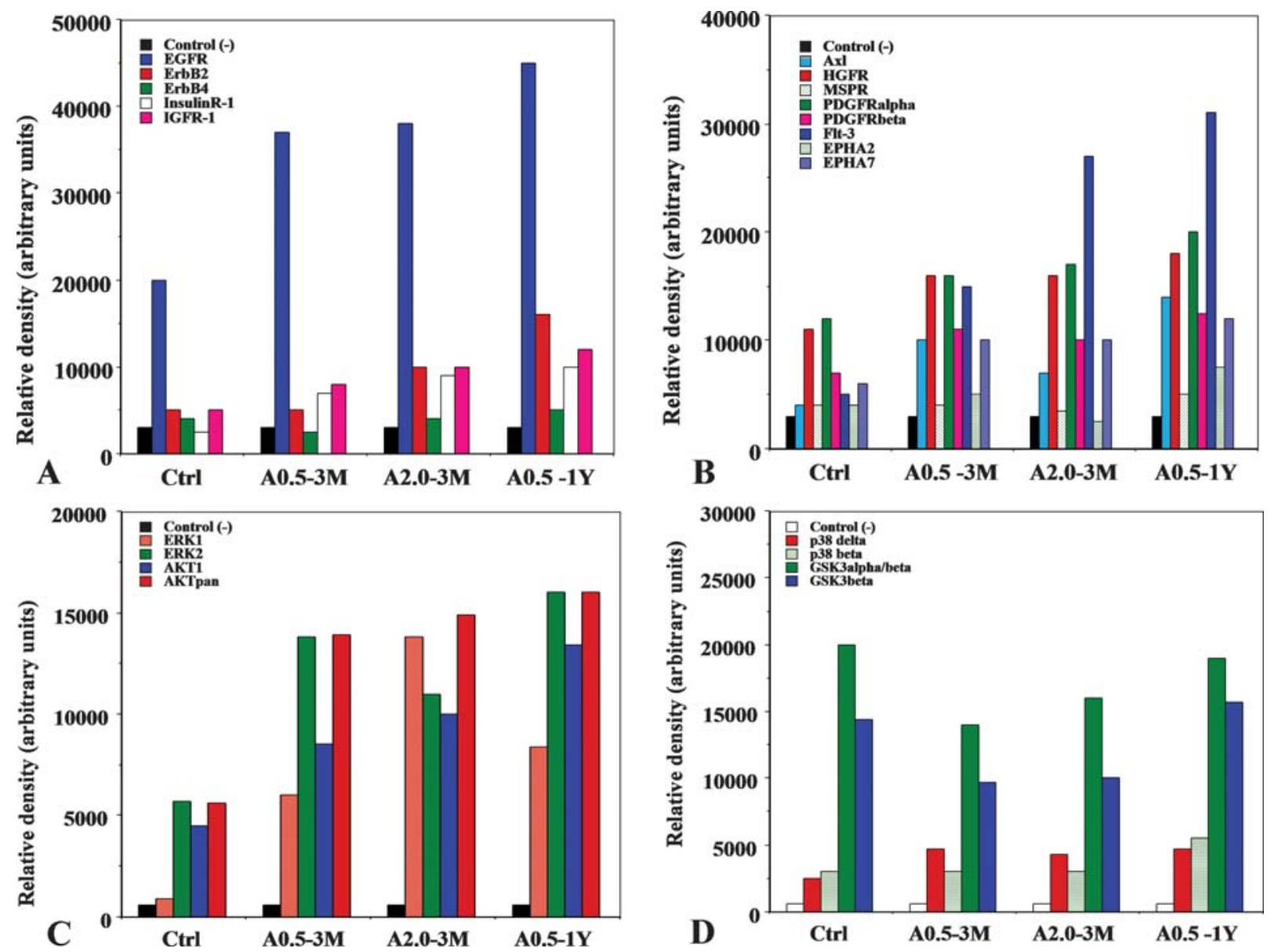

Figure 2. Phosphoproteomic profiles of arsenite-treated SAEC cells in comparison to control cells (Ctrl). Quantification of phosphorylation of different (A) receptor tyrosine kinases (RTKs), (B) mitogen-activated protein kinases (MAPKs), (C) extracellular signal-regulated kinases (ERKs and AKTs), and (D) p38 isoforms $(\Delta, \beta)$, GSK3 $(\alpha / \beta)$, GSK3 (ß) in arsenite-treated SAEC cells with different doses and different time periods.

Treatment with specific inhibitors of tyrosine kinase receptor. The GW2974 [Synonym N4-(1-Benzyl-1H-indazol-5-yl)N6,N6-dimethyl-pyrido(3,4-d) pyrimidine-4,6-diamine] (Sigma-Aldrich, St. Louis, MO) is a dual-specific inhibitor of both EGFR and ErbB2 and is able to effectively reduce TPAinduced AKT phosphorylation as well as TPA-stimulated EGFR and ErbB2 tyrosine phosphorylation in a dosedependent manner. The working concentration was $1 \mu \mathrm{M}$. The HNMPA inhibitor (hydroxy-2-naphthalenylmethylphosphonic acid (Biomol International, L.P., Plymouth, PA) is an insulin receptor with no effect on protein kinase $\mathrm{C}$ or cyclic AMP-dependent protein kinase activities but inhibits both the receptor serine and tyrosine phosphorylation. The working concentration was $100 \mu \mathrm{M}$. Lastly, 2-(3,4-dimethoxybenzoylamino)-4,5,6,7-tetrahydro-benzothiophene-3carboxylic acid (Sigma-Aldrich) was used as an inhibitor for Flt3R and the working concentration was $1 \mu \mathrm{M}$.

\section{Results}

The h-TERT immortalized SAEC cells were treated with different doses of arsenite for both short and long periods of time to study phenotypic alterations. Cells grew as a contactinhibited monolayer with a population doubling time of $\sim 24 \mathrm{~h}$. At confluence, these cells had a saturation density of $\sim 1.19 \times 10^{5}$ cells $/ \mathrm{cm}^{2}$ dish (26). The cells were continuously treated with sodium arsenite at $0.5 \mu \mathrm{g} / \mathrm{ml}$ for $\sim 3$ months or 1 year or with $2.0 \mu \mathrm{g} / \mathrm{ml}$ for $\sim 3$ months. The growth rate of arsenite exposed SAEC cells (Fig. 1A) indicated that there was an exponential phase of 3 to 7 days and reaching a plateau after 9 days. Both control and cells treated with different doses of arsenite grew in the same manner. Arsenite-treated cells grew much faster in comparison with the non-treated control. Long-term treatment showed more pronounced growth compared to short-term arsenite treatment. Saturation density for long-term treated cells increased almost 1.5-fold compared to control in the same duration of time. For short-term treatments, higher concentration of arsenite treatment gave slightly higher growth rate compared to lower concentration of arsenite treatment. Such results indicated that in short-term (e.g., 3 months), changing concentration of arsenite from low dose $(0.5 \mu \mathrm{g} / \mathrm{ml})$ to high dose $(2.0 \mu \mathrm{g} / \mathrm{ml})$ only had modest effect on cell growth. Similarly, plating efficiency (Fig. 1B) also changed in a dose- and duration- dependent manner. Plating efficiency of arsenite-treated cells increased from 11 to $22 \%$ for long-term (e.g., 1 year) arsenite treatment compared to control, non-treated cells. The plating efficiency of SAEC treated with $0.5 \mu \mathrm{g} / \mathrm{ml}$ and $2.0 \mu \mathrm{g} / \mathrm{ml}$ arsenite in short-term (e.g., 3 months) was increased to 13 and $18 \%$, respectively. Anchorage-independent growth ability of the 


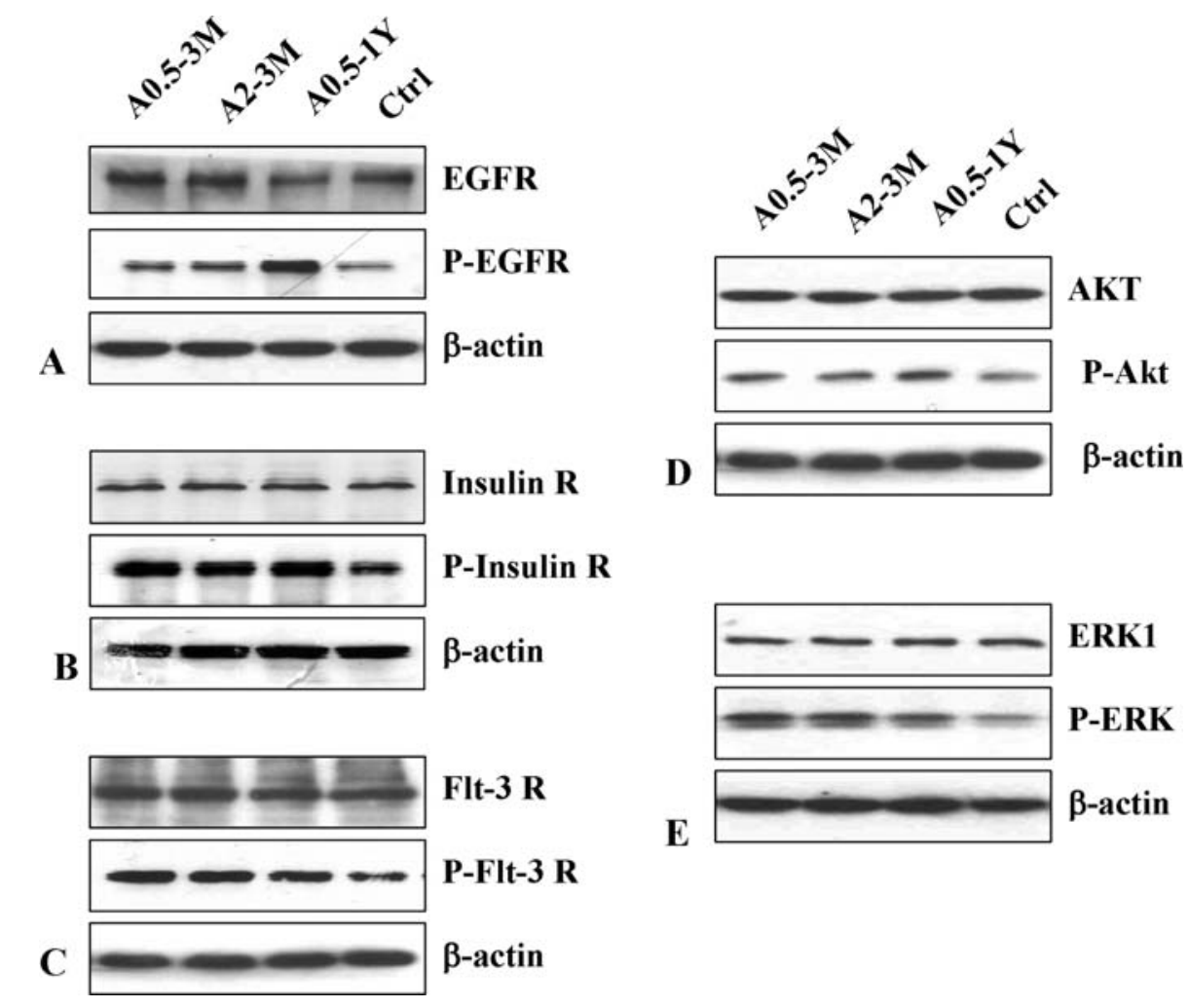

Figure 3. Protein expression of receptor tyrosine kinases and mitogen-activated protein kinases (MAPKs) in arsenite-treated SAEC cells. Phospho-levels and total levels of RTKs: (A) P-EGFR and EGF, (B) P-Insulin R and Insulin R, (C) Flt-3R and Flt-3R, (D) P-AKT and AKT, (E) P ERK and ERK1. B-actin was used as standard and loading controls.

arsenite-treated SAEC cells was also altered in a dose- and time-dependent manner. There was a significant difference in the number of colonies for arsenite-treated cells in comparison to control. There was no formation of colonies in soft-agar in control cells; however, there was an increase in the number of colonies with 0.5 and $2.0 \mu \mathrm{g} / \mathrm{ml}$ arsenite for 3 months scored as 28 and $24 \%$, respectively (Fig. 1C) and a dramatic increase in this anchorage-independent growth in long-term treatment $(0.5 \mu \mathrm{g} / \mathrm{ml}, 1$ year $)$.

Since arsenite treatment altered the growth rate, plating efficiency and anchorage-independent growth of SAEC, the phosphoproteomic profiles of phospho-RTKs and phosphoMAPKs in the arsenite-treated SAEC cells in parallel with non-arsenite exposed control (Fig. 2A-D) were analyzed. Results indicated that there were significant changes in phosphorylation status of many RTK members. In Fig. 2 it can be observed that most of these alterations were upregulated several fold when treated with different doses of arsenite for different period of time, such as EGFR, ErbB2, ErbB4, InsulinR-1, IGFR-1 (Fig. 2A), and Axl, HGFR (Fig. 2B) as seen by the relative density (arbitrary units). However, phosphorylation of certain RTKs such as MSPR and ErbB4 remained relatively unchanged in the same array (Fig. 2A and B). In a separate array, significant changes in many phospho-MAPK members were observed (Fig. 2C). Interestingly, MAPKs that are closely related with neoplastic progression of cells such as ERK1/2 and AKT1 exhibited the most dramatic changes. The up-regulation of phospho-MAPKs increased several fold when treated with different doses of arsenite at different period of time. Some MAPKs, on the other hand, showed a decrease at the phosphorylation level post arsenic exposure, such as GSK3 $\alpha / \beta$ and GSKß (Fig. 2D). To confirm changes in phosphorylation levels in the altered arsenite-treated cells, EGFR, Insulin R, Flt-3R, AKT1 and ERK1 were analyzed by Western blotting. Significant increase in protein expression was found in the phosphorylation in these proteins in comparison with the control SAEC cells as seen in EGFR (Fig. 3A), InsulinR (Fig. 3B), Flt-3R (Fig. 3C), and AKT (Fig. 3D), and ERK1 (Fig. 3E).

Specific inhibitors were used to block phosphorylation of these proteins to confirm that there were significant changes in arsenite-treated cells. GW2974 was used as a specific inhibitor for Flt3R, EGFR and InsulinR. As shown in Fig. 4A, inhibitors reduced cell proliferation rate indicated by the fluorescence intensity of arsenite-treated cells and among all these inhibitors, EGFR was the most effective and gave a maximum decline in cell numbers. Plating efficiency of each group decreased with RTK inhibitors such as cells treated for 3 months (A2.0-3M and $\mathrm{A} 0.5-3 \mathrm{M})$ and it was significantly lower in cells treated with A0.5 arsenite for a year, which had the highest plating efficiency when compared with the control (Fig. 4B). Inconsistent with the proliferation results, EGFR-I exhibited a more potent effect than the other two inhibitors, especially in cells with higher plating efficiency. Similarly, a remarkable change was observed in anchorageindependent growth with the RTK inhibitors (Fig. 4C). The decrease in colony number upon treatment with RTK inhibitors was most dramatic in the group that had the highest anchorage-independent growth such as the A0.5-1Y group. 

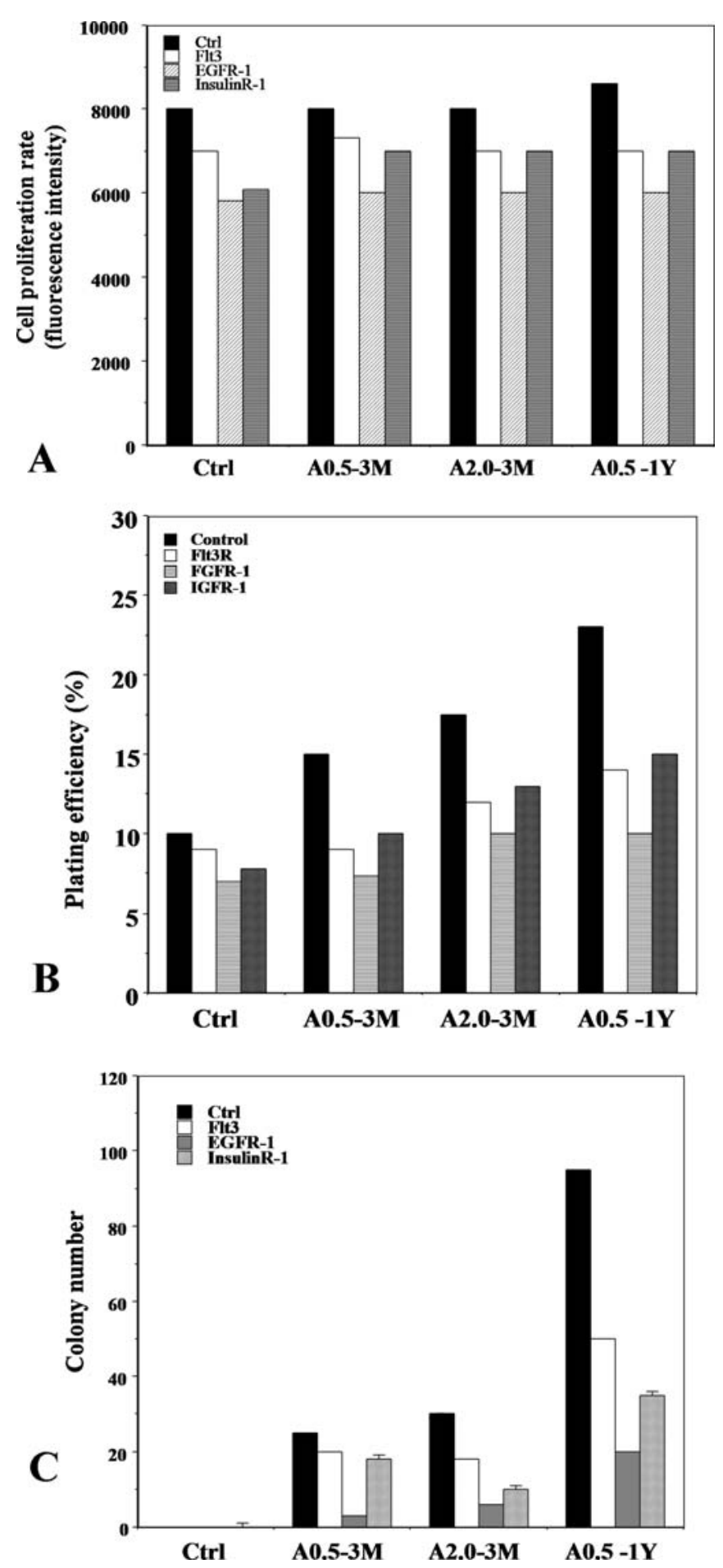

Figure 4. Growth characteristics of arsenite-treated SAEC cells by the effect of RTK specific inhibitors: (A) Cell proliferation rate (fluorescence intensity), (B) plating efficiency, (C) anchorage-independent growth ability indicated by colony number. The GW2974 was used as a specific inhibitor for EGFR and reduced cell growth, plating efficiency and anchorage-independent growth of arsenite-treated SAEC cells. The 2-(3, 4-dimethoxy-benzoylamino)4,5,6,7-tetrahydro-benzothiophene-3-carboxylic acid was used as an inhibitor for Flt3R $(1 \mu \mathrm{M} / \mathrm{ml})$.

\section{Discussion}

Immortalized human small airway epithelial cells were used in these studies to analyze the phosphoproteomes of two major signaling cascades, the Phospho-RTK pathway and the
MAPK. Neoplastic transformation of human small airway epithelial cells induced by arsenite has been previously reported (32). In the present study, Phospho-RTK that included EGFR, ErbB2, ErbB4, InsulinR-1, IGFR-1, Flt3it, was analyzed. The MAPKs included extracellular signalregulated kinases (ERK1/2), intracellular kinases such as AKT, GSK-3, p70 S6, c-Jun N-terminal kinases (JNK1-3) and different $\mathrm{p} 38$ isoforms $(\alpha / \beta / \delta / \gamma)$.

EGFR was one of the most important proteins that showed alteration in its phosphorylation level after arsenite treatment among the altered phosphoproteomic profiling of arsenitetreated human small airway. It has been suggested that levels of extracellular domain of EGFR in serum may be used as a biomarker to monitor the effect of arsenic exposure and to predict individuals at a greater risk of developing arsenicinduced skin lesions after the exposure (33). Moreover, arsenite and arsenate were found to activate extracellular signal-regulated kinases $1 / 2$ through an EGFR-mediated pathway in normal human keratinocytes (34). In addition, the combined treatment of EGFR inhibitors and arsenite has been demonstrated to enhance apoptosis in human EGFR-positive melanomas. This process may involve a direct suppression of the PI3K-AKT and MAPK pathways (35). The regulatory role of EGFR protein in arsenite-treated SAEC cells was also established by the use of GW2974, a specific inhibitor for EGFR. Treatment of GW2974 reduced cell growth, plating efficiency and anchorage-independent growth of arseniteexposed SAEC cells. Therefore, phosphorylation of EGFR in response to prolonged treatment of arsenite correlated well with the existing cell models.

Other altered protein in the RTK pathways such as InsulinR also seems to play an important role in arsenite-induced toxicity since it showed $~ 3-4$ fold change in the phosphorylation level after prolong treatment with arsenite. Altered expression of insulin receptor in type 2 diabetes mellitus has already been reported in different cell lines. Trivalent metabolites of inorganic arsenite [(iAs(III)] and methylarsonous acid [(MAs(III)] were demonstrated to inhibit insulinstimulated glucose uptake (ISGU) in 3T3-L1 adipocytes. Moreover, the suppression of the PDK-1/PKB/AKT-mediated transduction step is the key mechanism for the inhibition, and possibly for impaired glucose tolerance associated with human exposures to iAs $(36,37)$. It has been shown that transplacental arsenite exposure at a carcinogenic dose could produce aberrant estrogen-linked pulmonary gene expression in a mouse model. The insulin growth factor system that can be affected by estrogen receptor was also activated in fetal lung after gestational arsenic exposure (38). Interestingly, research also showed that arsenite and insulin exhibit opposing effects on epidermal growth factor receptor during arsenite induced keratinocyte proliferation (39). The up-regulation of insulinR in the arsenite-treated SAEC cells also suggested the involvement of this protein in the cellular responses to chronic arsenite treatment and thus establishing a link between arsenite exposure and the receptor tyrosine kinase signaling.

Another protein that showed a dramatic change in the phospho-RTK array was Flt3-R that exhibited an increase of several fold in phosphorylation level in arsenite-treated SAEC cells. Flt3-R usually serves as a candidate target gene 
for a second mutation in $\sim 40 \%$ of human acute promyelocytic leukemia cases. Mutations in Flt3, including internal tandem duplication, occur in the juxtamembrane domain at which arsenite trioxide is the most potent signal transducer $(40,41)$. Flt3 internal tandem duplication is a prevalent mutation in various signaling pathways including the MAPK/extracellular signal-regulated kinase (ERK) pathway (18). However, to the best of our knowledge, the role of Flt3 in phospho-receptor tyrosine kinase pathway has not been documented in other systems. Therefore, our finding in this study may implicate a novel role of Flt3-R in arsenite-induced responses and further studies will be needed to reveal the molecular mechanisms related with such response.

Our results also indicated that certain MAPKs are activated by arsenite treatment. ERK1/2 as an important member of the MAPK pathway has been shown to be activated by exposure to combustion-derived metals in human bronchial epithelial cells (42). It was also demonstrated that ERK $1 / 2$ is activated by As (+3) in human lung adenocarcinoma cells (43). Inconsistent with these previous observations, our results showed $>9$-fold increase in ERK1/2 phosphorylation. Further studies on the underlying mechanisms of this up-regulation will shed light on how ERK1/2 exerts its critical role in arsenite-induced toxicity.

Arsenite has been used as a chemotherapeutic drug to treat acute promyelocytic leukemia cases (44). Thus, sodium arsenite seems to trigger caspase activation by activation of AKT1 and downstream glycogen synthase $3 ß$ (GSK3ß), which are crucial for caspase signaling network AKT1 activation they also can act as an alternate cell survival pathway that is mediated via PI-3 kinase and p38 and bypass the activation of EGF receptor in cultured human keratinocytes (45). In the present study, both short-term and prolonged arsenite treatment induced AKT activation, though to a less extent compared with the activation of ERK. The activation of AKT in response to arsenite was confirmed by Western blotting, suggesting the involvement of AKT-related pathways in arsenite-induced toxicity in SAEC cells.

In conclusion, differential profiling of pathway specific phosphoproteins can elucidate different stages of the carcinogenic process, which is induced by different doses and duration of arsenite treatment. Studies on both short- and long-term exposures can provide valuable comparative information on prolonged genetic alterations associated with slow and steady arsenite exposure as occur in natural condition. These phosphoproteins are also related with other important proteins in different cell cycle pathways. Therefore, information obtained in this study can be used to identify a common link among interrelated pathways in response to arsenite. The involvement of two important (e.g., RTKs and MAPKs) phosphoproteomes would contribute to the understanding of the genetic and epigenetic regulations in arsenite-exposed cells. As arsenite is one of the major pollutants for inducing lung cancer, results obtained from growth curve, plating efficiency and anchorage-independent growth of arsenitetreated SAEC cells is helpful in the study of arsenite-induced carcinogenesis. Future studies to elucidate the underlying molecular and cellular mechanisms based on our phosphoproteomic data will help to specify the role of arsenite as a toxic substance as well as a chemotherapeutic agent.

\section{Acknowledgements}

This work was supported by National Institute of Health grants ES 05786, ES 11804, Superfund grant P42 ES 10349 and Environmental Center Grant ES 09089. Thanks are given to Convenio de Desempeño Universidad de Tarapacá-Mineduc, Universidad de Tarapacá, Arica, Chile (GMC).

\section{References}

1. Bode AM and Dong Z: The paradox of arsenite: molecular mechanisms of cell transformation and chemotherapeutic effects. Crit Rev Oncol Hematol 42: 5-24, 2002.

2. Basu A, Mahata J, Gupta S and Giri AK: Genetic toxicology of a paradoxical human carcinogen, arsenite: a review. Mutat Res 488: 171-194, 2001.

3. Morales KH, Ryan L, Kuo TL, Wu MM and Chen CJ: Risk of internal cancers from arsenite in the drinking water. Environ Health Perspect 108: 655-661, 2000.

4. Aposhian HV: Arsenite toxicology: does methylation of arsenite species have an evolutionary significance? Met Ions Biol Med 4: 399-401, 1996.

5. Marshall G, Ferreccio C, Yuan Y, Bates MN, Steimaus C, Liaw J and Smith AH: Fifty-year study of lung and bladder cancer mortality in Chile related to arsenite in drinking water. J Natl Cancer Inst 99: 920-928, 2007.

6. Chowdhury TR, Basu GK, Mandal BK, et al: Arsenite poisoning in the Ganges delta. Nature 401: 545-546, 1999.

7. National Research Council: Arsenite in Drinking Water. National Academy Press, Washington, DC, 2000.

8. Tseng WP, Chu HM, How SW, Fong JM, Lin CS and Yeh S: Prevalence of skin cancer in an endemic area of Chronic arseniteism in Taiwan. J Natl Cancer Inst 40: 453-463, 1968.

9. Cebrián ME, Albores A, Aguilar M and Blakely E: Chronic arsenite poisoning in the north of Mexico. Hum Toxicol 2: 121-133, 1983.

10. IARC: Some drinking-water disinfectants and contaminants, including arsenic. Working group on the Evaluation of Carcinogenic Risks to Humans. IARC Monogr Eval Carcinog Risks Hum 84: 1-477, 2004.

11. Lee TC, Oshimura M and Barrett JC: Comparison of arseniteinduced cell transformation, cytotoxicity, mutation and cytogenetic effects in Syrian hamster embryo cells in culture. Carcinogenesis 6: 1421-1426, 1985.

12. Hei TK, Liu SX and Waldren C: Mutagenicity of arsenite in mammalian cells: Role of reactive oxygen species. Proc Natl Acad Sci USA 95: 8103-8107, 1998.

13. Gurr JR, Lin YC, Ho IC, Jan KY and Lee TC: Induction of chromatid breaks and tetraploidy in Chinese hamster ovary cells by treatment with sodium arsenite during the G2 phase. Mutat Res 319: 135-142, 1993.

14. Wang TS and Huang H: Active oxygen species are involved in the induction of micronuclei by arsenite in XRS-5 cells. Mutagenesis 9: 253-257, 1994.

15. Chen CJ and Wang CJ: Ecological correlation between arsenite level in well water and age-adjusted mortality from malignant neoplasms. Cancer Res 5: 5470-5474, 1990.

16. Liu SX, Athar M, Lippai I, Waldren C and Hei TK: Induction of oxyradicals by arsenite: Implication for mechanism of genotoxicity. Proc Natl Acad Sci USA 98: 1643-1648, 2001.

17. Cavigelli M, Li WW, Lin A, Su B, Yoshioka K and Karin M: The tumor promoter arsenite simulates AP-1 activity by inhibiting a JNK phosphatase. EMBO J 15: 6269-6279, 1996.

18. Samet JM, Graves LM, Quay J, et al: Activation of MAPKs in human bronchial epithelial cells exposed to metals. Am J Physiol 275: L551-L558, 1998.

19. Reichard JF, Schnekenburger M and Puga A: Long term lowdose arsenite exposure induces loss of DNA methylation. Biochem Biophysic Res Commun 352: 188-192, 2007.

20. Wu W, Graves LM, Jaspers I, Devlin RB, Reed W and Samet JM: Activation of the EGF receptor signaling: pathway in human airway epithelial cells exposed to metals. Am J Physiol 277: L924-L931, 1999.

21. Wilbourne J, Haroun L, Heseltine E, Kaldor J, Partensky D and Vainio V: Response of experimental animals to human carcinogens: an analysis based upon the IARC monographs programme. Carcinogenesis 7: 1853-1863, 1986. 
22. Lau AT, He QY and Chiu JF: Proteomic technology and its biomedical applications. Acta Biochim Biophys Sin 35: 965-975, 2003.

23. Jungblut PR, Zimny-Arndt U, Zeindl-Eberhart E, et al: Proteomics in human disease: cancer, heart and infectious diseases. Electrophoresis 20: 2100-2110, 1999.

24. Mumby M and Brekken D: Phosphoproteomics: new insights into cellular signaling. Genome Biol 6: 230, 2005.

25. Gembitsky DS, Lawlor K, Jacovina A, Yaneva M and Tempst P: A prototype antibody microarray platform to monitor changes in protein tyrosine phosphorylation. Mol Cell Proteomics 3: 1102-1118, 2004.

26. Piao CQ, Liu L, Zhao YL, Balajee AS, Suzuki M and Hei TK: Immortalization of human small airway epithelial cells by ectopic expression of telomerase. Carcinogenesis 26: 725-731, 2005.

27. Samet JM, Silbajoris R, Wu W and Graves LM: Tyrosine phosphatases as targets in metal-induced signaling in human airway epithelial cells. Am J Respir Cell Mol Biol 21: 357-364, 1999.

28. Engelman JA, Zejnullahu K, Mitsudomi T, et al: MET amplification leads to gefitinib resistance in lung cancer by activating ERBB3 signaling. Science 316: 1039-1043, 2007.

29. Hober S and Uhlén M: Human protein atlas and the use of microarray technologies. Curr Opin Biotechnol 19: 30-35, 2008.

30. Roy D, Calaf G and Hei TK: Profiling of differentially expressed genes induced by high linear energy transfer radiation in breast epithelial cells. Mol Carcinogen 31: 192-203, 2001.

31. Lei T, He QY, Cai, Z, et al: Proteomic analysis of chromium cytotoxicity in cultured rat lung epithelial cells. Proteomics 8: 2420-2429, 2008.

32. Wen G, Calaf GM, Partridge MA, et al: Neoplastic transformation of human small airway epithelial cells induced by arsenite. Mol Med 14: 2-10, 2008.

33. Tanaka-Kagawa T, Hanioka N, Yoshida H, Jinno H and Ando M Arsenite and arsenate activate extracellular signal-regulated kinases $1 / 2$ by an epidermal growth factor receptor-mediated pathway in normal human keratinocytes. Br J Dermatol 149: 1116-1127, 2003.

34. Ivanov VN and Hei TK: Combined treatment with EGFR inhibitors and arsenite upregulated apoptosis in human EGFRpositive melanomas: a role of suppression of the PI3K-AKT pathway. Oncogene 24: 616-626, 2005.

35. Díaz-Villaseñor A, Burns AL, Hiriart M, Cebrián ME and Ostrosky-Wegman P: Arsenite-induced alteration in the expression of genes related to type 2 diabetes mellitus. Toxicol Appl Pharmacol 225: 123-133, 2007.
36. Paul DS, Harmon AW, Devesa V, Thomas DJ and Styblo M: Molecular mechanisms of the diabetogenic effects of arsenite: inhibition of insulin signaling by arsenite and methylarsonous acid. Environ Health Perspect 115: 734-742, 2007.

37. Shen J, Liu J, Xie Y, Diwan BA and Waalkes MP: Fetal onset of aberrant gene expression relevant to pulmonary carcinogenesis in lung adenocarcinoma development induced by in utero arsenite exposure. Toxicol Sci 95: 313-320, 2007.

38. Patterson TJ and Rice RH: Arsenite and insulin exhibit opposing effects on epidermal growth factor receptor and keratinocyte proliferative potential. Toxicol Appl Pharmacol 221: 119-128, 2007.

39. Wetzler M, Brady MT, Tracy E, et al: Arsenite trioxide affects signal transducer and activator of transcription proteins through alteration of protein tyrosine kinase phosphorylation. Clin Cancer Res 12: 6817-6825, 2006.

40. Amadori S, Fenaux P, Ludwig H, O'Dwyer M and Sanz M: Use of arsenite trioxide in haematological malignancies: insight into the clinical development of a novel agent. Curr Med Res Opin 21: 403-411, 2005

41. Takahashi S, Harigae H, Yokoyama H, et al: Synergistic effect of arsenite trioxide and Flt 3 inhibition on cells with Flt 3 internal tandem duplication. Int J Hematol 84: 256-261, 2006.

42. Cheng Y, Chang LW and Tsou TC: Mitogen-activated protein kinases mediate arsenite-induced down-regulation of surviving in human lung adenocarcinoma cells. Arch Toxicol 80: 310-318, 2006.

43. Hossain K, Akhand AA and Kawamto Y: Caspase activation is accelerated by the inhibition of arsenite-induced, membrane-raftsdependent AKT activation. Free Radic Biol Med 34: 598-606, 2003.

44. Souza K, Maddock DA, Zhang Q, Chen J, Chiu C, Mehta S and Wan Y: Arsenite activation of P13K/AKT cell survival pathway is mediated by p38 in cultured human keratinocytes. Mol Med 7: 767-772, 2001

45. Pramanik R, Qi X, Borowicz S, Choubey D, Schultz RM, Han J and Chen G: p38 isoforms have opposite effects on AP-1 dependent transcription through regulation of c-Jun. The determinant roles of the isoforms in the p38 MAPK signal specificity. J Biol Chem 278: 4831-4839, 2003. 